\title{
Cholera toxin (CTX) genetic element in Vibrio cholerae 0139
}

\author{
Rupak K. Bhadra, Susanta Roychoudhury, Rajat K. Banerjee, Sujata Kar, \\ Ruma Majumdar, Sanghamitra Sengupta, Soma Chatterjee, \\ Gopal Khetawat and Jyotirmoy Das
}

Biophysics Division, Indian Institute of Chemical Biology, 4 Raja S. C. Mullick Road, Calcutta 700 032, India

\begin{abstract}
Author for correspondence: Susanta Roychoudhury. Fax: +91 33473 0350/0284. e-mail: iicb\%sirnetc@sirnetd.ernet.in
\end{abstract}

\begin{abstract}
PFGE analysis of the Noti- and Sfil-digested genome of Vibrio cholerae 0139 strains isolated from different epidemic regions of India showed that all the strains are of clonal origin and the genome size is about 2.2 Mb. An analysis of the electrophoretic profiles of the genome of 0139 strains, the RFLP of the cholera toxin (ctx) gene and Southern blot hybridization of Noti-digested genomes of classical, El Tor and 0139 with a Nott-linking clone of classical strain 569B, suggest that these strains closely resemble $V$. cholerae 01 biotype El Tor, but are widely different from the classical 01 vibrios. Using restriction enzymes which cleave a single site in either the core region or in the direct repeat sequence (RS) of the CTX genetic element, it has been shown that the genome of most of the 0139 strains has two copies of the ctx gene in tandem connected by two RSs. The chromosomal location of the CTX genetic element in the 0139 strain is the same as that reported for El Tor vibrios. The organization of the virulence gene cassettes in different 0139 strains shows genetic heterogeneity in the population. Whilst most of the epidemic strains have two copies of the CTX genetic element, in some strains the number of elements has been amplified and in at least one strain a single copy of the element has been deleted.
\end{abstract}

\section{Keywords: Vibrio cholerae $\mathrm{O} 139$, cholera toxin, virulence cassette, integration site,} linking clones

\section{INTRODUCTION}

The outbreak of a cholera epidemic in India and Bangladesh in latter half of 1992 , which subsequently spread into several parts of the subcontinent, was due to the emergence of a novel non-O1 strain of Vibrio cholerae, O139 Bengal (Albert et al., 1993a; Ramamurthy et al., 1993). Previous cholera epidemics had been caused by $V$. cholerae serogroup O1, whilst non-O1 serogroups were responsible for causing only sporadic infections. Several studies have reported conflicting results regarding the origin of the O139 strain. From studies on the RFLP of whole genomes (Berche et al., 1994) and of different virulence genes (Calia et al., 1994; Iida et al., 1993; Waldor \& Mekalanos, 1994a), polymixin B sensitivity (Albert $e t$ al., 1993b), outer-membrane protein profile (Calia et al., $1994)$ and sensitivity to choleraphages ( $R$. Chowdhury, personal communication), it has been suggested that the

Abbreviations: CTX, cholera toxin; RS, repeated sequence.
O139 strain is very similar to the El Tor biotype of O1 vibrios and might have originated from the latter. On the other hand, studies on the organization of the cholera toxin (CTX) genetic element by Lebens \& Holmgren (1994) have suggested that O139 strains resemble the classical biotype of $V$. cholerae.

The organization of the $\operatorname{ctx} A B$ gene in the $V$. cholerae $\mathrm{O} 1$ genome has been delineated (Mekalanos, 1983; Pearson $e t$ al., 1993) and can be used as one of the differentiating criteria between the O1 biotypes (Mekalanos, 1983). The gene encoding cholera toxin (ctx) is located on a $4.5 \mathrm{~kb}$ DNA segment, flanked by two or more copies of a direct repeat sequence (RS) varying in length from 2.4 to $2.7 \mathrm{~kb}$ (Pearson et al., 1993). The $4.5 \mathrm{~kb}$ core region contains genes encoding the zonula occludens toxin (zot), accessory cholera enterotoxin (ace), an unknown ORF (orf $U$ ) and core-encoded pilus (cep), as well as $c t x A B$ (Baudry et al., 1992; Pearson et al., 1993; Trucksis et al., 1993). In most $V$. cholerae $\mathrm{O} 1$ strains this CTX genetic element is present in more than one copy. In strains of El Tor biotype the 
Table 1. $V$. cholerae strains used

\begin{tabular}{|c|c|c|}
\hline Strain & Source/origin & Serotype/biotype/CT gene* \\
\hline \multicolumn{3}{|c|}{ A. Current epidemic } \\
\hline MO1 & Clinical, Madras, India & $\mathrm{O} 139, \mathrm{CT}^{+}$ \\
\hline $\mathrm{MO} 28$ & Clinical, Madras, India & $\mathrm{O} 139, \mathrm{CT}^{+}$ \\
\hline MDO12 & Clinical, Madurai, India & $\mathrm{O} 139, \mathrm{CT}^{+}$ \\
\hline MDO25 & Clinical, Madurai, India & $\mathrm{O} 139, \mathrm{CT}^{+}$ \\
\hline VO15 & Clinical, Vellore, India & $\mathrm{O} 139, \mathrm{CT}^{+}$ \\
\hline AP1 & Clinical, Andhra Predesh, India & $\mathrm{O} 139, \mathrm{CT}^{+}$ \\
\hline AP2 & Clinical, Andhra Pradesh, India & $\mathrm{O} 139, \mathrm{CT}^{+}$ \\
\hline PO2 & Clinical, Pune, India & $\mathrm{O} 139, \mathrm{CT}^{+}$ \\
\hline PO7 & Clinical, Pune, India & $\mathrm{O} 139, \mathrm{CT}^{+}$ \\
\hline SG24 & Clinical, Calcutta, India & $\mathrm{O} 139, \mathrm{CT}^{+}$ \\
\hline SG25 & Clinical, Calcutta, India & $\mathrm{O} 139, \mathrm{CT}^{+}$ \\
\hline CO54 & Clinical, Calcutta, India & O139, $\mathrm{CT}^{+}$ \\
\hline \multicolumn{3}{|c|}{ B. Other strains } \\
\hline $569 \mathrm{~B}$ & Clinical, India & O1, classical, $\mathrm{CT}^{+}$ \\
\hline NIH35A3 & Clinical, India & $\mathrm{O} 1$, classical, $\mathrm{CT}^{+}$ \\
\hline NIH41 & Clinical, India & O1, classical, $\mathrm{CT}^{+}$ \\
\hline $\mathrm{O} 395$ & Clinical, India & $\mathrm{O} 1$, classical, $\mathrm{CT}^{+}$ \\
\hline $\mathrm{V} 18$ & Clinical, India & $\mathrm{O} 11, \mathrm{CT}^{-}$ \\
\hline V34 & Clinical, India & $\mathrm{O} 11, \mathrm{CT}^{-}$ \\
\hline V64 & Clinical, India & O1, El Tor, $\mathrm{CT}^{+}$ \\
\hline V66 & Clinical, India & O1, El Tor, $\mathrm{CT}^{+}$ \\
\hline V90 & Clinical, India & O1, El Tor, $\mathrm{CT}^{+}$ \\
\hline V131 & Clinical, India & O1, El Tor, $\mathrm{CT}^{+}$ \\
\hline MAK757 & Clinical, Indonesia & O1, El Tor, $\mathrm{CT}^{+}$ \\
\hline V201 & Clinical, India & $\mathrm{O} 39, \mathrm{CT}^{-}$ \\
\hline V254 & Clinical, India & OUK, $\mathrm{CT}^{-}$ \\
\hline VCE309 & Environmental, India & OUK, $\mathrm{CT}^{-}$ \\
\hline VC42 & Clinical, Japan & $\mathrm{O} 42, \mathrm{CT}^{-}$ \\
\hline
\end{tabular}

*OUK, O-serogroup unknown.

CTX genetic elements are arranged in tandem and in classical strains they are widely separated on the chromosome (Mekalanos, 1983). The organization of the CTX genetic elements in non-O1 vibrios is not known. Regarding the organization of the CTX genetic element in O139 strains, it has recently been reported (Lebens \& Holmgren, 1994) that the $\operatorname{ct} x A B$ gene, together with the genes associated with the virulence cassette, is located at two loci, a situation similar to that in classical vibrios. In contrast, studies by Waldor \& Mekalanos (1994b) have indicated that the organization of the CTX genetic element in the genome of O139 strains is similar to that in El Tor vibrios.

The results presented in this report from PFGE analysis and the analysis of enzyme-digested classical, El Tor and O139 genomes by Southern blot hybridization using several probes show that the organization of the CTX genetic elements and their location in the genome of O139 strains is similar to that reported for El Tor vibrios. Whilst most of the O139 strains carry two copies of the CTX genetic element, some heterogeneity with respect to the number and chromosomal location of this element have also been observed.

\section{METHODS}

Bacterial strains and growth conditions. $V$. cholerae strains used in this study are described in Table 1 . All strains were obtained from the National Institute of Cholera and Enteric Diseases, Calcutta, India. Bacteria were routinely grown in a gyratory shaker at $37^{\circ} \mathrm{C}$ in nutrient broth containing $0.1 \mathrm{M}$ $\mathrm{NaCl}(\mathrm{pH} \mathrm{8 \cdot 0)}$.

PFGE. Intact chromosomal DNA embedded in $0.5 \%$ agarose blocks for PFGE were isolated and digested with restriction endonucleases. Electrophoresis was carried out in a Pulsaphor Plus System with hexagonal electrode array (Pharmacia) as described previously (Roychoudhury et al., 1994). The pulse time was ramped between 5 and $20 \mathrm{~s}$ for NotI-digested DNA, and 5 and $25 \mathrm{~s}$ for Sfil-digested DNA for $22 \mathrm{~h}$ at $10 \mathrm{~V} \mathrm{~cm}^{-1}$.

Nick-translation and Southern blot analysis. About $1 \mu \mathrm{g}$ of a 780 bp $N d e I$ fragment from the ctx gene in plasmid pCVD15 (Dasgupta et al., 1994) and a $2.3 \mathrm{~kb}$ BglII-PstI fragment, also from this plasmid, containing part of a RS and the cep gene of the CTX genetic element (Pearson et al., 1993) was nick-translated using $\left[\alpha_{-}{ }^{32} \mathrm{P}\right] \mathrm{dCTP}$ (Amersham) and DNA polymerase I as described previously (Roychoudhury et al., 1994).

For Southern blot experiments, about 1-2 $\mu \mathrm{g}$ of $V$. cholerae genomic DNA was digested with the desired restriction 
endonucleases and fragments were electrophoretically separated, the gels were irradiated with UV light to nick the DNA, denatured, neutralized and blotted to nytran membranes. Hybridization was carried out at $60^{\circ} \mathrm{C}$. The filters were washed under stringent conditions, dried and exposed to Kodak XOMAT AR5 film.

\section{RESULTS AND DISCUSSION}

\section{PFGE analysis of 0139 strains}

The genomic DNA of O139 strain (Table 1) from different epidemic areas were analysed by PFGE following digestion with NotI or SfiI. The digestion profiles of all the epidemic strains were identical (Fig. 1a). This is not surprising in view of the fact that the isolates from different epidemic zones are of clonal origin (Bhadra et al., 1994; Shimada et al., 1993). Using phage $\lambda$-multimeric DNA and $\lambda$-HindIII fragments as molecular mass markers, the fragment sizes were estimated. The NotI fragment sizes of all the O139 strains used were similar and represented a genome of approximately $2 \cdot 2 \mathrm{Mb}$ (Table 2 ). A comparison of the DNA restriction enzyme digestion profile of the O139 strain with that of DNA from strains belonging to serovar $\mathrm{O} 1$ and other non-O1 strains (data not shown) showed that the O139 genome more closely resembles $\mathrm{El}$ Tor strains. Two NotI fragments of the genome of biotype $\mathrm{El}$ Tor (Fig. 1a, lanes 8 and 9, arrowheads) were absent in NotI-digested O139 genomic DNA, and one Sfil fragment of O139 genomic DNA (Fig. 1a, lanes 13-17, arrowhead) was missing in SfiI-digested El Tor genomic DNA (Fig. 1a, lanes 18-21). Except for these differences, the NotI and SfiI digestion profiles of $\mathrm{El}$ Tor and $\mathrm{O} 139$ genomes were almost identical. Minor variations were, however, always observed even between different El Tor strains, as well as in classical strains.

The similarity between the El Tor and O139 genomes became more apparent from Southern blot hybridization of NotI- (Fig. 1b, lanes 4 and 5) and SfiI- (Fig. 1b, lanes 8 and 9) digested DNA using $\operatorname{ctx} A$ as probe. The $\operatorname{ctx} A$ probe hybridized with the same NotI (Fig. 1b, lanes 1-4) or SfI (Fig. 1b, lanes 9-12) fragments of all O139 strains. In contrast, the $c t x$ probe hybridized with two different NotI- and Sfil-digested fragments of the genome of the classical strain (Fig. 1b, lanes 6 and 7). The El Tor strain used in this experiment has a single copy of $c t x A B$ (this study). ctx $A$ hybridized with a $7.0 \mathrm{~kb}$ NotI fragment of the El Tor genome (Fig. 1b, lane 5), as observed with one of the two $\mathrm{O} 139$ ctx gene copies. The $\operatorname{ctx} A$ probe also hybridized to the same SfiI DNA fragment in the El Tor genome (Fig. 1b, lane 8) as observed for $\mathrm{O} 139$ genomes (Fig. 1b, lanes 9-12). The ctx $A$ probe hybridized with two NotI fragments of the $\mathrm{O} 139$ genome (Fig. 1b), suggesting there are two copies of the CTX genetic element in the O139 genome that are either widely separated or present in tandem with one NotI site in the genetic element itself. We have shown that there is a NotI site in the CTX genetic element of O139 strains (Bhadra et al., 1994) similar to that reported for El Tor O1 strains (Pearson $e t$ al., 1993). Thus, there are two copies of the CTX genetic element in tandem in O139 strains.
While constructing physical maps of the genomes of representative $V$. cholerae $\mathrm{O} 1$ and non-O1 strains, we have generated several linking clone libraries using different enzymes (unpublished data). One of the NotI-linking clones of the genome of classical strain 569B was randomly picked and used as probe in Southern blot hybridization of NotI-digested genomes of strains 569B (classical, O1), MAK757 (El Tor, O1) and SG24 (non-O1, O139). The linking clone used hybridized with the same two fragments in MAK757 and SG24 (Fig. 2). The NotI-digested genome of the classical strain 569B, however, hybridized with one fragment common to and another fragment different from MAK757 and SG24 (Fig. 2). These results showed that the 50 and $20 \mathrm{~kb}$ fragments (Fig. 2) are linked to each other in MAK757 and SG24 genomes. Thus, it is very likely that $\mathrm{O} 139$ strains have evolved from $\mathrm{El}$ Tor strains of $\mathrm{O} 1$ vibrios. This conclusion was further substantiated from restriction analysis of the virulence cassette.

\section{Organization of CTX genetic element in 0139 strains}

Single $A v a \mathrm{I}$ and $P_{s t \mathrm{I}}$ sites are present in the core region of the CTX genetic element of O1 vibrios (Mekalanos, 1983). In Southern blot hybridization of AvaI- or PstIdigested genomic DNA of O139 strains using a nicktranslated NdeI fragment of ctx A (Dasgupta et al., 1994) as probe, two fragments hybridized with the probe (Fig. 3). In addition to a $14.3 \mathrm{~kb}(A v a \mathrm{I})$ and a $5.8 \mathrm{~kb}$ fragment $(P s t \mathrm{I})$, a $9.3 \mathrm{~kb}$ fragment hybridized with the $c t x A$ probe in both AvaI- and PstI-digested O139 genomic DNA, similar to the observations reported for El Tor strains with two copies of the CTX genetic element present in tandem (Mekalanos, 1983). These results confirm that there are two copies of the CTX genetic element in the O139 genome and that they are present in tandem. Since the sizes of the core region and the RS of the CTX genetic element are about 4.5 and $2.4 \mathrm{~kb}$, respectively, the $9.3 \mathrm{~kb}$ common fragment must contain two RS segments. The two core regions are therefore connected by two RS segments (Fig. 4) in the O139 genome.

Bg/II has a single site in the RS of the CTX genetic element of O1 vibrios (Pearson et al., 1993). If both the CTX genetic elements of O139 strains were flanked by the RS on both sides, then only one fragment would hybridize following $B g / I I$ digestion of the genomic DNA using ctx $A$ as probe. In contrast, if one of the CTX genetic elements was not flanked by a RS on both sides, two fragments would hybridize. The results presented here (Fig. 3) show that two $B g / I$ fragments of 7.0 and $8.1 \mathrm{~kb}$ hybridized with the $\operatorname{ctx} A$ probe. Hence, in O139 strains one element is not flanked by an RS segment. To show which element is not flanked by a RS, O139 genomic DNA was digested with EcoRV, which has one site in the RS (Pearson et al., 1993) and one in the core region of the CTX genetic element of O1 vibrios (Trucksis et al., 1993), and hybridized with the $c t x A$ probe. If the RS was present downstream of the second element, only one fragment of size $4.0 \mathrm{~kb}$ would hybridize. In contrast, if the RS was present upstream of the first element, then two fragments 
(a)
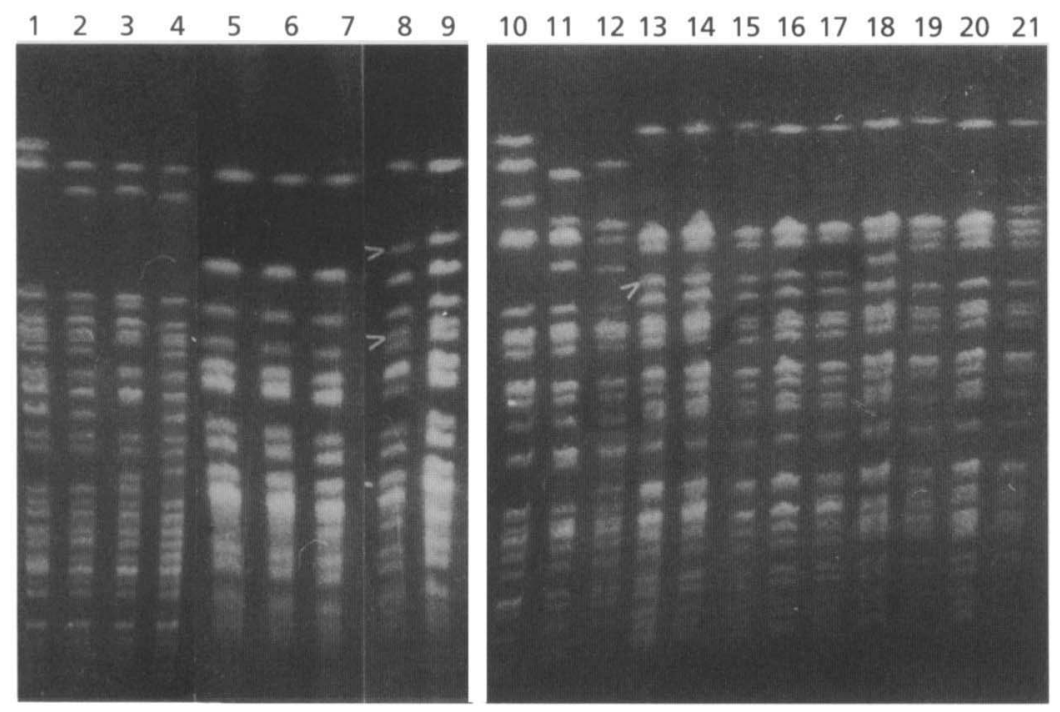

(b)

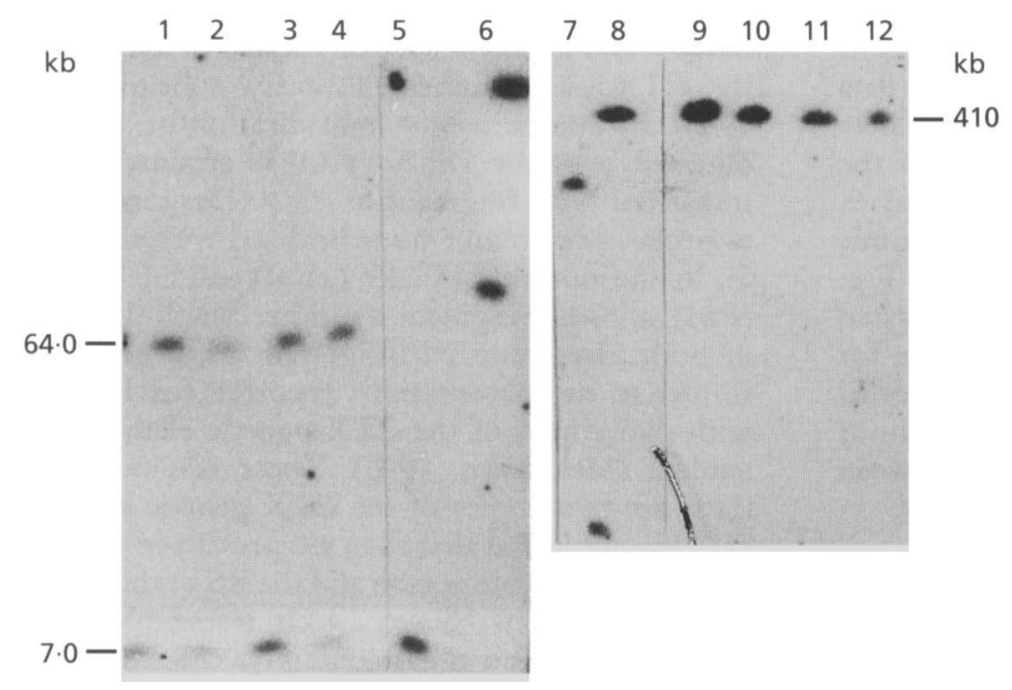

Fig. 1. (a) PFGE of Notl- (lanes 1-9) and Sfil(lanes 10-21) digested genomes of $V$. cholerae strains. The digested DNA was separated on $1 \%$ Fast lane agarose (FMC) with pulse time ramping between 5 and $20 \mathrm{~s}$ at $10 \mathrm{~V} \mathrm{~cm}^{-1}$ for $22 \mathrm{~h}$ (lanes 1-9) and 5 and $25 \mathrm{~s}$ at $10 \mathrm{~V} \mathrm{~cm}-1$ for $22 \mathrm{~h}$ (lanes 10-21). Lanes: 1 and 10, NIH35A3; 2, NIH41; 3 and 11, 0395; 4 and 12, 569B; 5 and 13, MO28; 6 and 14, SG24; 7 and 15, SG25; 8 and 20 , V90; 9 and 21 , V131; 16, PO7; 17, CO54; 18, V64; 19, V66. Arrowheads indicate bands as described in Results and Discussion. (b) Southern blot hybridization of Notl- (lanes 1-6) and Sfil- (lanes 7-12) digested genomes of $V$. cholerae strains using ctxA as probe. Hybridization was carried out at $60^{\circ} \mathrm{C}$. The filters were washed under stringent conditions. Lanes: 1 and 9, SG24; 2, VO15; 3 and $10, A P 1 ; 4, P O 7 ; 5$ and $8, V 90 ; 6$ and 7 , 569B; 11, MO28; 12, MDO12. would hybridize, one of them being $4.0 \mathrm{~kb}$ (Fig. 4). The results presented here show that 4.0 and $3.5 \mathrm{~kb}$ fragments were generated following EcoRV digestion of O139 genomic DNA (Fig. 3). Thus, the first CTX genetic element has an RS on both sides and there is no RS downstream of second element (Fig. 4). Therefore, the CTX genetic element present in O139 strains and that in O1 vibrios have identical physical maps and their organization is similar to that reported for El Tor biotypes which have two copies of the CTX genetic element.

The organization of the CTX genetic element in O139 strains was further confirmed using the Bg/II-PstI fragment (Fig. 4) of the cassette which contains the RS region and part of the core. When AvaI-digested genomic DNA of an $\mathrm{O} 139$ strain was hybridized with this probe, three bands of 17, 14.3 and $9.3 \mathrm{~kb}$ hybridized (Fig. 3). As expected, the 14.3 and $9.3 \mathrm{~kb}$ fragments were detected by both $c t x$ and RS probes. The $17 \mathrm{~kb}$ fragment was attributed to the upstream RS of the element. An RS probe also hybridized with three $B g / I$ fragments of which 8.1 and $7 \mathrm{~kb}$ fragments were detected by both $c t x$ and RS probes. The $2.8 \mathrm{~kb}$ fragment was from the RS connecting the two core elements (Fig. 3). Using XbaI-digested O139 genomic DNA and probes from different regions of the CTX genetic element, Waldor \& Mekalanos (1994b) have recently drawn a similar conclusion.

\section{Chromosomal location of the CTX genetic element}

Mekalanos (1983) demonstrated that the CTX genetic element in all El Tor strains examined and one of the elements of the classical strain 569B are located at the same chromosomal site. To examine whether the CTX genetic elements in the O139 genome are also located at the same site, the genomic DNA of O139 strain SG24, classical strain 569B and El Tor strain MAK757 were digested with AvaI, PstI, BglII or EcoRV and Southern blot hybridization was carried out using $\operatorname{ctx} A$ as probe. Two 
Table 2. Size of Notl-digested fragments of the $V$. cholerae 0139 genome

The values are for the representative strain, SG24.

\begin{tabular}{|lclc|}
\hline Fragment & Size (kb) & Fragment & Size (kb) \\
\hline A & 316 & Q & 48 \\
B & 204 & R & 42 \\
C & 166 & S & 40 \\
D & 144 & T & 36 \\
E & 128 & U & 30 \\
F & 120 & V & 26 \\
G & 108 & W & 20 \\
H & 102 & X & 18 \\
I & 92 & Y & 14 \\
J & 84 & Z & 13 \\
K & 80 & AA & 12 \\
L & 72 & AB & 10 \\
M & 68 & AC & 8 \\
N & 66 & AD & 7 \\
O & 60 & AE & 6 \\
P & 54 & Total & $\mathbf{2 1 9 4}$ \\
\hline
\end{tabular}

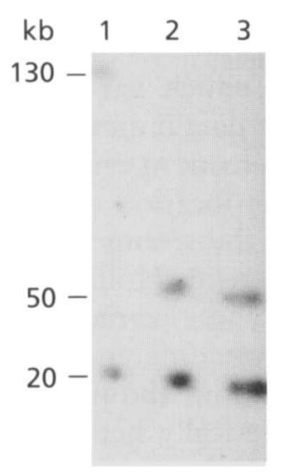

Fig. 2. Southern blot hybridization of Notl-digested $V$. cholerae genomes using a Notl-linking clone of the genome of 01 classical strain 569B as probe. This clone links Notl fragments $K$ and $Y$ of the 569B genome (Roychoudhury et al., 1994). Hybridization was carried out as described in the legend to Fig. 1(b). Lanes: 1, 569B; 2, SG24 ; 3, MAK757. fragments hybridized with the probe following digestion with each of the above restriction enzymes (Fig. 5). For Pst I digestion a $5.8 \mathrm{~kb}$ fragment was found to be common to all strains (Fig. 5a). Similarly, for $B g / \mathrm{II}$ (Fig. 5b), EcoRV (Fig. 5c) and AvaI (data not shown) $8.1,3.5$ and $14.3 \mathrm{~kb}$ fragments, respectively, were found to be common to all strains. These common fragments originate from one site in the CTX genetic element and one in the adjacent chromosomal segment (Fig. 4). A $9.3 \mathrm{~kb}$ Pst I fragment was found to be common to the classical O1 strain and O139 strain SG24 (Fig. 5a, lanes 2 and 3). A similar observation was reported by Lebens \& Holmgren (1994) which led them to conclude that the chromosomal location of the CTX genetic element in O139 strains is similar to that in the classical vibrios. However, results obtained using other enzymes which have sites in the CTX genetic element (Fig. 5b,c) do not support their conclusion. Thus, in O139 strains the CTX genetic elements in the chromosome are probably located at the same site as in El Tor strains and one of the two copies of the CTX element of the classical vibrios. This is in contrast to a recent report by Faruque et al. (1994) where, from the comparison of the RFLP of $\operatorname{ctx} A$, it has been concluded that the chromosomal locations of the ctx genes in $\mathrm{O} 139$ strains are unlike those of the El Tor or classical vibrios.

\section{Instability of the CTX element in 0139}

Although the PFGE profile of the NotI- and SfiI-digested genome of O139 strain SG25, isolated from Calcutta, India, was identical to other O139 strains, the present study suggests that with respect to organization and chromosomal location of the CTX genetic element, this strain is different from the other isolates examined. In Southern blot hybridization of NotI-, AvaI- and Bg/IIdigested SG25 DNA using the $c t x A$ gene as probe, only one fragment hybridized (Fig. 6) in contrast to two fragments for other strains. Furthermore, the sizes of the fragments hybridizing with the $\operatorname{ct} x A$ gene, for all the enzymes examined, were different from those of the other strains. Thus, SG25 has one copy of the CTX genetic element and it is located at a site different from those in
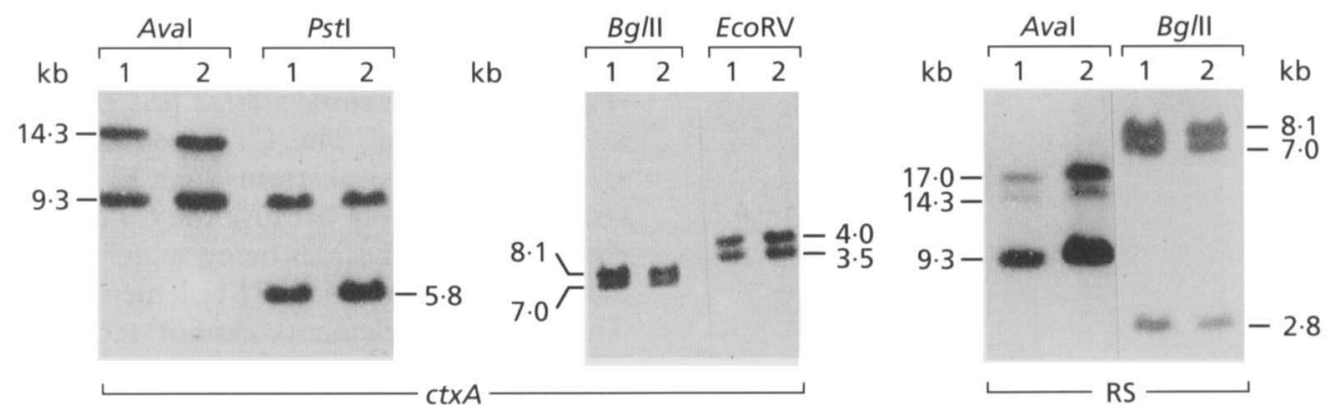

Fig. 3. Southern blot hybridization of Aval-, Pstl-, Bglll- and EcoRV-digested $V$. cholerae 0139 genomes using ctxA or RS as probe. The hybridization was carried out as described in the legend to Fig. 1(b). Lanes: 1, SG24; 2, PO7. 

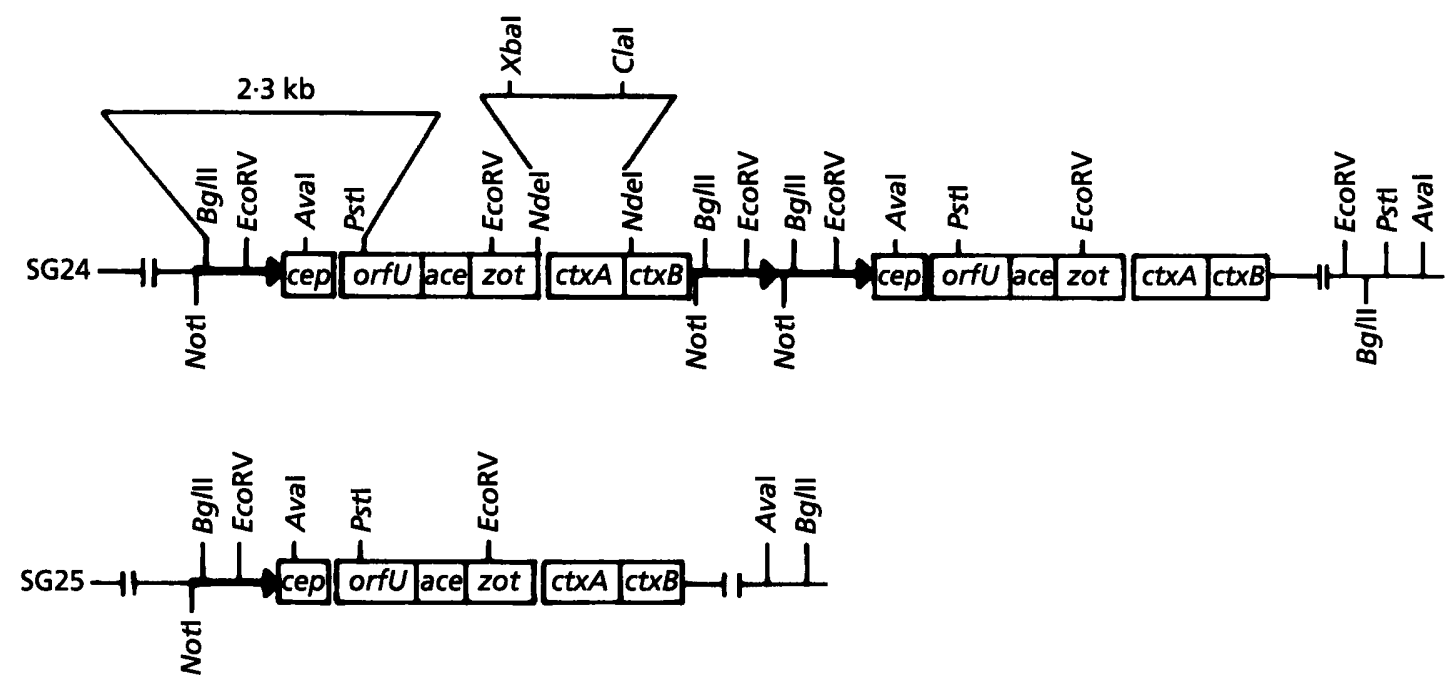

Fig. 4. Schematic representation of the organization of the CTX genetic element in V. cholerae 0139 strains SG24 and SG25 (not drawn to scale). Open boxes are coding regions of corresponding genes. Thick arrows represent RSs and thin lines represent chromosomal DNA. The $780 \mathrm{bp}$ Ndel fragment of the ctx loci and the $2.3 \mathrm{~kb}$ Bg/ll-Pstl fragments were used as ctx and RS probes, respectively.

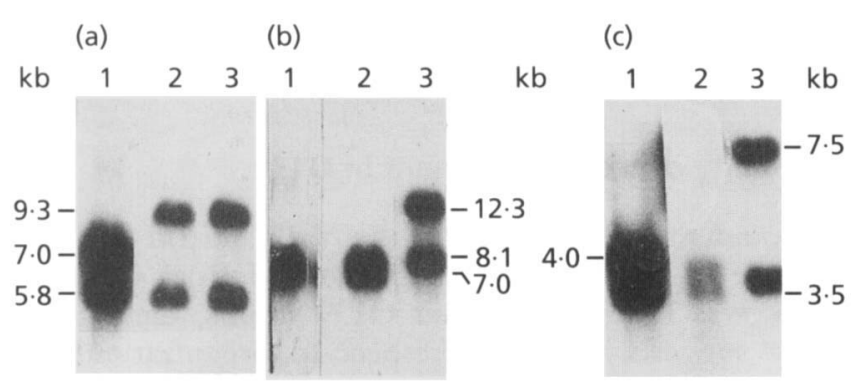

Fig. 5. Southern blot hybridization of (a) Pstl-, (b) Bg/ll- and (c) ECORV-digested genomes of MAK757 (lane 1), SG24 (lane 2) and 569B (lane 3) using ctxA as probe. The hybridization was carried out as described in the legend to Fig. 1(b).

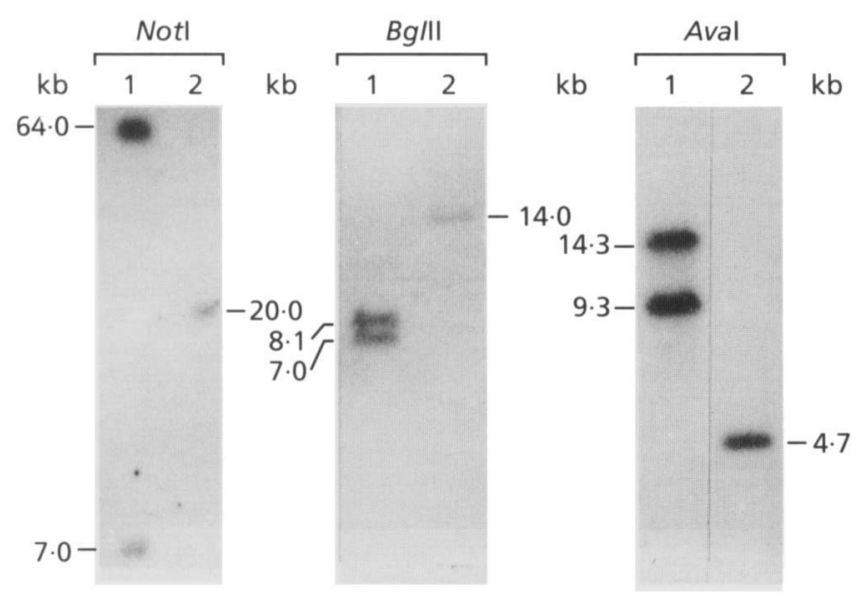

Fig. 6. Southern blot hybridization of Notl-, Bg/ll- and Avaldigested genomes of SG24 (lane 1) and SG25 (lane 2) using ctxA as probe. The hybridization was carried out as described in the legend to Fig. 1(b). other $\mathrm{O} 139$ strains. This observation was confirmed using RS as a probe (data not shown).

Besides strain SG25, which has one copy of the CTX genetic element, other data indicate that the organization of the CTX genetic element in certain O139 strains differs in the number and the location of the virulence cassette compared to most of the strains which have two copies (Iida et al., 1993; Lebens \& Holmgren, 1994; Waldor \& Mekalanos, 1994b). These variations, even in a small collection of strains from different epidemic zones, reflect that the O139 population, though considered to be of clonal origin, are genetically heterogeneous. Within the span of an epidemic such variations in the virulence genes are unusual and unexpected. Considering the fact that most of the epidemic strains have two copies of the CTX genetic element, it appears that some strains have amplified the number of these elements and in some, one of the elements has been deleted, as in the case of SG25 reported here. Such genetic heterogeneity was also observed for $\mathrm{El}$ Tor strains isolated during the seventh cholera pandemic. It should be noted that all the classical vibrios examined so far have two copies of the CTX genetic element which are widely separated in the chromosome. In contrast, most of the El Tor strains carry one copy of the ctx gene (Betley et al., 1986) with some strains possessing multiple copies in tandem repeat. The CTX genetic elements are more stable in the classical strains than El Tor biotype or O139 strains, presumably because the CTX genetic elements in classical strains, besides being widely separated, are never flanked on both sides by RS1 elements (Mekalanos, 1983). Thus the RS1 elements cannot recombine and lead to amplification and/or deletion events. In contrast, in both El Tor biotype or O139 strains, one or both copies of the CTX genetic elements are flanked by RS1. Thus, the stability/instability of the CTX genetic element is determined not only by the presence of the elements in 
tandem but also by the presence of RS1 on one or both sides of the element.

\section{ACKNOWLEDGEMENTS}

We thank Dr. G. B. Nair of NICED, Calcutta, India, for the O139 strains of $V$. cholerae. We are grateful to all members of the Biophysics Division for kind cooperation and encouragement during the study. The work was supported by the Department of Biotechnology [Grant No. BT/TF/15/03/91], Government of India. R. M. and S.C. are grateful to the Council of Scientific and Industrial Research, New Delhi, for pre-doctoral fellowships.

\section{REFERENCES}

Albert, M. J., Siddique, A. K., Islam, M. S., Faruque, A. S. G., Ansaruzzaman, M., Faruque, S. M. \& Sack, R. B. (1993a). Large outbreak of clinical cholera due to Vibrio cholerae non-O1 in Bangladesh. Lancet 341, 704.

Albert, M. J., Ansaruzzaman, M., Bardhan, P. K., Faruque, A. S. G., Faruque, S. M., Islam, M. S., Mahalanabis, D., Sack, R. B., Salam, M. A., Siddique, A. K., Yunus, M. D. \& Zaman, K. (1993b). Large epidemic of cholera-like disease in Bangladesh caused by Vibrio cholerae O139 synonym Bengal. Lancet 342, 387-390.

Baudry, B., Fasano, A., Ketley, J. \& Kaper, J. B. (1992). Cloning of a gene (zot) encoding a new toxin produced by $V$ ibrio cholerae. Infect Immun 60, 428-434.

Berche, P., Poyart, C., Abachin, E., Lelievre, H., Vandepitte, J., Dodin, A. \& Fournier, J.-M. (1994). The novel epidemic strain O139 is closely related to the pandemic strain $\mathrm{O} 1$ of Vibrio cholerae. J Infect Dis 170, 701-704.

Betley, M. J., Miller, V. L. \& Mekalanos, J. J. (1986). Genetics of bacterial enterotoxins. Annu Rev Microbiol 40, 577-605.

Bhadra, R. K., Roychoudhury, S. \& Das, J. (1994). Vibrio cholerae O139 El Tor biotype. Lancet 343, 728.

Calia, K. E., Muratagh, M., Ferraro, M. J. \& Calderwood, S. B. (1994). Comparison of Vibrio cholerae $\mathrm{O} 139$ with $V$. cholerae $\mathrm{O} 1$ classical and El Tor biotypes. Infect Immun 62, 1504-1506.

Dasgupta, U., Bhadra, R. K., Panda, D. K., Deb, A. \& Das, J. (1994). Recombinant derivative of a naturally occurring non-toxinogenic Vibrio cholerae O1 expressing the B subunit of cholera toxin: a potential oral vaccine strain. Vaccine 12, 359-364.
Faruque, S. M., Abdulalim, A. R. M., Roy, S. K., Khan, F., Nair, G. B., Sack, R. B. \& Albert, M. J. (1994). Molecular analysis of rRNA and cholera toxin genes carried by the new epidemic strain of toxigenic Vibrio cholerae $\mathrm{O} 139$ synonym Bengal. J Clin Microbiol 32, 1050-1053.

lida, T., Shrestha, J., Yamamoto, K., Honda, T. \& Albert, M. J. (1993). Cholera isolates in relation to the 'eighth pandemic'. Lancet 342, 926.

Lebens, M. \& Holmgren, J. (1994). Structure and arrangement of the cholera toxin genes in Vibrio cholerae O139. FEMS Microbiol Lett 117, 197-202.

Mekalanos, J. J. (1983). Duplication and amplification of toxin genes in Vibrio cbolerae. Cell 35, 253-263.

Pearson, G. D. N., Woods, A., Chiang, S. L. \& Mekalanos, J. J. (1993). CTX genetic element encodes a site-specific recombination system and an intestinal colonization factor. Proc Natl Acad Sci US $A$ 90, 3750-3754.

Ramamurthy, T., Garg, S., Sharma, R., Bhattacharya, S. K., Nair, G. B., Shimada, T., Takeda, T., Karasawa, T., Kurazano, H., Pal, A. \& Takeda, Y. (1993). Emergence of novel strain of Vibrio cholerae with epidemic potential in southern and eastern India. Lancet 341, 703-704.

Roychoudhury, S., Bhadra, R. K. \& Das, J. (1994). Genome size and restriction fragment length polymorphism analysis of $V$ ibrio cholerae strains belonging to different serovars and biotypes. FEMS Microbiol Lett 115, 329-334.

Shimada, T., Nair, G. B., Deb, B. C., Albert, M. J., Sack, R. B. \& Takeda, Y. (1993). Outbreak of Vibrio cholerae non-O1 in India and Bangladesh. Lancet 341, 1346.

Trucksis, M., Galen, J. E., Michalski, J., Fasano, A. \& Kaper, J. B. (1993). Accessory cholera enterotoxin (Ace), the third toxin of a Vibrio cholerae virulence cassette. Proc Natl Acad Sci US A 90, 5267-5271.

Waldor, M. K. \& Mekalanos, J. J. (1994a). ToxR regulates virulence gene expression in non-O1 strains of Vibrio cholerae that cause epidemic cholera. Infect Immun 62, 72-78.

Waldor, M. K. \& Mekalanos, J. J. (1994b). Emergence of a new cholera pandemic: molecular analysis of virulence determinants in $V$ ibrio cholerae $\mathrm{O} 139$ and development of a live vaccine prototype. $J$ Infect Dis 170, 278-283.

Received 14 December 1994; revised 24 March 1995; accepted 20 April 1995. 